\title{
El derecho a la ficción ${ }^{1}$
}

Más que hacer un recorrido histórico de cómo la literatura salvadoreña ha reflejado (o se ha inventado) la identidad nacional, preferiría hacer unas breves reflexiones sobre la relación entre literatura e identidad nacional, expresión cuyo uso corriente - confieso- no deja de producirme alguna incomodidad. Para ello, recurro a una cuestión central en la literatura, la ficción, esa verdad de las mentiras, para emplear la expresión no del todo feliz de Vargas Llosa.

Y digo que esa expresión no es feliz porque induce a que reduzcamos el significado de la palabra ficción al de mentira, o al accidente arbitrario y caprichoso de la imaginación. La imaginación, facultad sólo a medias reconocida por la tradición filosófica, es mucho más importante de lo que solemos aceptar. Creo así que estaremos más cerca de la verdad si entendemos ficción como invención, como creación activa y prospectiva, como aquello que nos permite vernos más allá de la inmediatez de los hechos. Así, la ficción resulta responder a una necesidad antropológica y no a un simple lujo de ociosos.

Es, en este sentido, pues, que la nacionalidad, la identidad nacional es primaria y ulteriormente una ficción. Nos inventamos la nación de los relatos (historias), la identidad nacional resulta ser un meta relato, un relato de relato, una historia hecha a partir de historias, o si se prefiere, historietas. La nación se inventa como un decantado de historias y memorias, de dominación y resistencia, de opresión y liberación.

La nacionalidad no es, pues, una esencia, algo dado de antemano y desde siempre. Por el contrario, es una ficción que debe ser re-actualizada, es decir vuelta a contar, y por esta misma razón puede ser re-escrita, re-inventada.

La nación es, por tanto, resultante de historias $y$ relatos que circulan en la sociedad y que son vehiculadas a través de distintos medios y en diversas constelaciones de significación: las ideologías políticas, el discurso oficial, la publicidad, las conversaciones cotidianas, la Historia (con hache mayúscula) y de una manera mucho menos visible las prácticas artísticas. Ahora bien, esta circulación dista de ser fluida y armoniosa, es un espacio en disputa, donde los distintos grupos de poder entran en juego para alcanzar la hegemonía simbólica de una sociedad a partir de quién y para quién define la náción.

El espacio de la literatura, y aquí pienso fundamentalmente en los géneros narrativos (pido ahora disculpas a los poetas), ha jugado un papel importante en esta dinámica y es, quizá, la práctica social que eleva esta realidad a un mayor grado de elaboración, complejidad y prospección.

Ricardo Piglia, novelista argentino, nos asiste con palabras que encuentro de una lucidez providencial: "un narrador ve a la sociedad como una

1. Comunicación presentada en la conferencia "El Salvador y los salvadoreños en Estados Unidos: identidad y lazos culturalcs", organizada por Asosal cn el hotcl Hollyday-Inn, Antiguo Cuscatlán, 1 I de agosto de 2000. 


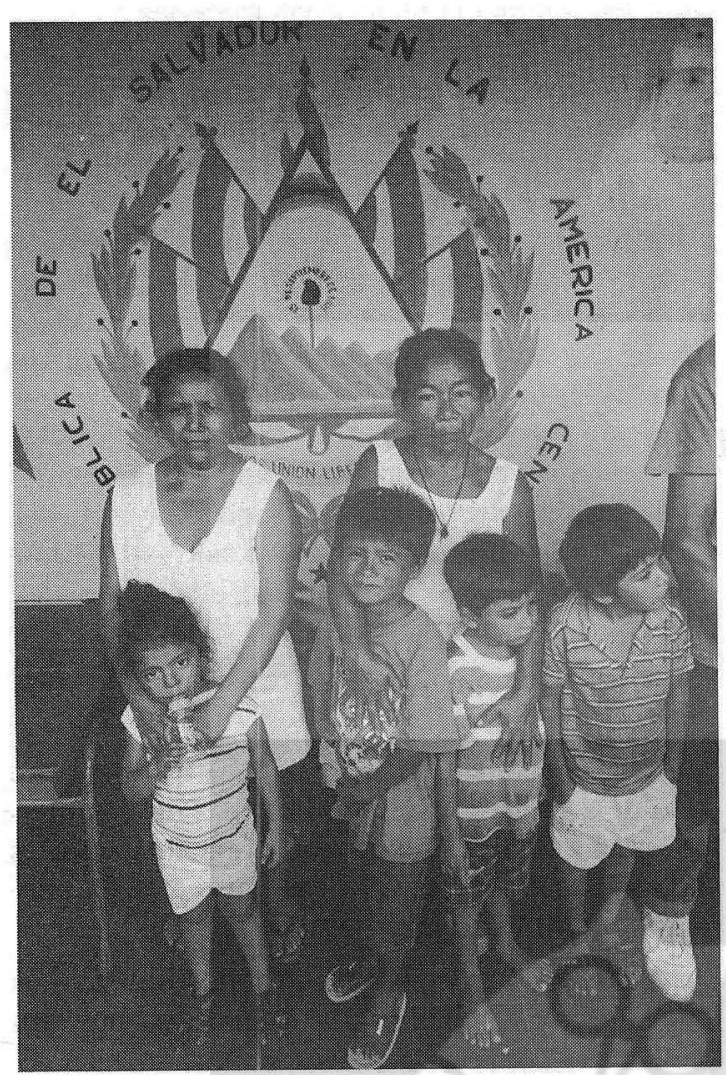

trama de relatos... son estructuras que nos determinan tanto como las estructuras de la lengua... si tuviéramos posibilidad de trabajar estas ficciones sociales, quizá veríamos que estas ficciones sociales son el contexto mayor de la literatura. Y que la novela en realidad, reproduce, interioriza y transforma -y preserva, diría yo- estas ficciones sociales. Yo creo que este es el modo en que la literatura se liga con lo social y lo político. Esa materia de la literatura es una materia que ya está ficcionalizada por este trabajo social de construcción de relatos y ficciones" (97-98).

Quisiera ahora pedir auxilio a un filósofo a quien admiro mucho, a Paul Ricoeur, para sacarle provecho a las lúcidas ideas del escritor. Con ello quisiera explicar la manera en que la literatura —en especial la ficción narrativa- tiene de relacionarse con lo real y, así de paso, subrayar la necesidad - el imperativo, el derecho, diría yo- de contar con un caudal rico de ficciones y relatos de carácter artístico, y dimensionar el déficit de imaginación -y de realidad- que nuestro país padece.
Para Ricoeur, la significación de la obra artística funciona en tres momentos (el habla de triple mímesis, pero dejemos de lado hoy la jerga de especialistas): prefiguración, configuración y transfiguración. La prefiguración es lo que Piglia describe con tanta eficacia: la riqueza de historias y formas que impregnan la vida social. La vida social está ya de antemano prefigurada en símbolos, historias e incluso formas literarias (valga la tautología). El pecado de muchas de las teorías formalistas, como señala alguno, no es darle demasiada importancia a las formas, sino darles demasiado poca, creer que son patrimonio exclusivo y excluyente de los literatos. Pensemos si no en las épicas a las que cotidianamente deben recurrir muchos de nuestros compatriotas para hacer sentido de su experiencia de llegada a la tierra prometida de Estados Unidos.

El segundo momento, la configuración, nos remite a la labor propia y reconocida del artista. El artista da forma. Confiere una forma superior a símbolos, formas e historias que forman una constelación, o mejor dicho, una nebulosa, si hemos de sacarle partido a esta metáfora astronómica. ¿En qué consiste, entonces, la forma propiamente artística? Ricoeur lo explica con una paradoja muy efectiva (también los filósofos tienen sus momentos de inspiración poética): "El lenguaje nos dice el mundo porque antes lo ha abandonado". Una construcción artística sólida tiene una doble exigencia: alimentarse de materiales de la "vida", pero disponerlos de tal forma que ese vínculo con la vida inmediata se pierda de vista momentáneamente. Eso es la ficción. Es salirnos del mundo de lo inmediato, de lo fáctico, para ir a lo que está más allá.

La transfiguración, en tercer lugar, comprende el momento ulterior de retorno del lenguaje al mundo luego de haberlo abandonado momentáneamente. Y aquí hay que tener claro cómo retorna el lenguaje literario, artístico, al mundo para no confundirlo con la manera en que otros modos de lenguaje nos dicen la realidad: como la ciencia o el lenguaje común. El lenguaje literario no retorna como una descripción, como una designación directa del referente inmediato de la experiencia. El juego de la configuración artística nos transfigura, es decir nos aguza los sentidos, nos abre los ojos a nuevas realidades que en nuestra experiencia inmediata de los hechos permanecían opacos, invisibles. Esto es posible, en la medida que la cons- 
trucción artística sea coherente y se nutra de las formas y significaciones sociales pre-existentes. Aquí no estoy abogando por un realismo a ultranza; entre prefiguración y configuración no existe ninguna relación de homogeneidad necesaria, la obra artística puede referirse a la realidad de manera directa o alusiva, de manera descriptiva o metafórica, etc..

Este proceso en el cual la ficción literaria amplía los horizontes del lector es importante para entender la manera dinámica en que la literatura interviene en la producción de identidades nacionales. No se trata simplemente de constatar y consignar preconceptos y prejuicios, sino de un proceso activo de reconocer e integrar lo novedoso, lo diverso, lo "otro", a la identidad. Por ello, en la literatura la identidad no puede entenderse sin el paso por la alteridad. Porque leer activamente, en el proceso de transfiguración que hemos descrito arriba, supone necesariamente despojarse de la identidad y sentir y experimentar con el otro y a través del otro.

Entender el papel de la literatura como de simple expresión de una identidad nacional ya dada es erróneo y no recoge lo mejor que tiene que ofrecernos. En la literatura siempre hay alteridad y prospección. Siempre hay un componente utópico, aun cuando sea de una utopía negativa, es decir, de anhelos que no se expresan de manera directa, sino que aparecen implicados en nuestro examen crítico del mundo que habitamos.

El aporte que la literatura puede dar para tener una visión más amplia de la identidad en nuestro país es muy grande. Ello por ciertas características propias de nuestra vida cultural. Quisiera esbozar el régimen de ficciones de nuestro país en las siguientes ideas.

* Escasez de ficciones elaboradas sobre la experiencia social. Lo nacional es efecto de discursos muy limitantes como la publicidad u otras manifestaciones altamente ideologizadas.

* Estas ficciones se limitan a consignar y, peor aún, a "esencializar" prejuicios y estereotipos que circulan sobre la "salvadoreñidad", sin examinar su plausibilidad o su vinculación con intereses políticos y sociales específicos. Pensemos en la publicidad y en discursos ideológicos de afirmación nacional. A mí siempre se me viene a la mente un chocante comercial de una bebida gaseosa que eleva a categoría de sublime una reducción chocarrera y vulgar de la creatividad de la lengua popular. Contrapongamos a esto, por ejemplo, la poesía que emana a borbotones de los personajes de Cuentos de Barro de Salarrué.

* Las ficciones literarias suelen ser un contrapeso saludable a esta tendencia, pero son escasas y su circulación y recepción es muy limitada. Por otro lado, dentro de este panorama poco alentador a la creación artística emanan dos problemas. En primer lugar, una pobre exploración de los sentidos (y especialmente de las ficciones sociales); hablar de experiencia social se ha vuelto una suerte de pecado en estos tiempos posmodernos; estamos bajo la tiranía de la intertextualidad; creer que hacer literatura es hacer un palimpsesto de citas literarias y pareciera que algunos escritores ya no aprecian tener un oído agudo para escuchar las historias de otros, para trascender su mismidad en diálogo con la alteridad. En segundo lugar, se puede caer en el pecado opuesto. Creer que consignar la experiencia social basta. Aquí el pecado es haber olvidado lo específico del trabajo literario, la transformación de la materia prima social en forma artística. Mucho de esto lo encontramos también en la literatura llamada testimonial o comprometida.

Hoy en día, al hablar de identidad nacional se suele pasar por alto o descalificar la literatura en virtud de su existencia marginal, es decir, en virtud de la marginalidad de sus cultivadores y consumidores. Yo creo que este problema no debe ser obviado por quienes hoy en día le sigan apostando a la importancia de la literatura como quehacer o como objeto de reflexión y estudio. He, por ello, querido exponer aquello que es propio de la literatura y que hasta ahora no existe otra práctica cultural capaz de sustituir.

La ficción literaria, especialmente la narrativa, no se limita a producir o reproducir mitologías sobre la identidad. Por el contrario, pareciera ser que más bien las desmitifica. A través de la interacción entre autor, obra y lector, la literatura es una exploración de la heterogeneidad que abarca todo espacio social. Y las construcciones literarias más audaces buscan integrar esta diversidad en una unidad superior, de mayor complejidad. En este sentido, la literatura pre-figura una labor social que todavía es asignatura pendiente en nuestro país. 
Por ello, sólo en este sentido de búsqueda de una unidad superior, compleja e internamente diversa, es que considera aceptable hablar de literatura e identidad. La nación no puede ser la reiteración de lo mismo, sobre todo cuando lo mismo nos postra y nos hunde en el letargo y la desesperación.

La literatura no sólo nos permite comprendernos mejor como somos, sino como somos distintos y diversos, y como desearíamos ser diferentes simplemente al mostrarnos en medio de nuestras miserias, ansiedad y esperanzas. Por eso creo que el derecho a la ficción, que no es otra cosa que el derecho a la imaginación y la libertad, debe defenderse con decisión. No sólo pensando en los artistas y sus deseos legítimos de expresión, sino desde la perspectiva de los pueblos y su derecho a la esperanza.

Ricardo Roque Baldovinos Antiguo Cuscatlán, agosto de 2000. 